\title{
Content and Outcomes of Social Work Consultation for Patients with Diabetes in Primary Care
}

\author{
Andrew J. Rabovsky, BS, Michael B. Rothberg, MD, MPH, \\ Susannah L. Rose, MSSW, PhD, Andrei Brateanu, MD, Lei Kou, MA, \\ and Anita D. Misra-Hebert, MD, MPH
}

Purpose: Social workers are positioned to address social determinants of health (SDHs), but their specific roles in outpatient primary care practice have not been well described. We aimed to describe needs of patients with diabetes addressed during social work (SW) consultations and their impact on disease control.

Methods: This study was a retrospective review of electronic medical records of 977 patients with diabetes with a SW consultation at 3 primary care internal medicine sites in 2014. Diabetes and cardiovascular (CV) risk factor control were assessed before and after the SW encounter. Patient subgroups with uncontrolled diabetes or CV risk factors were compared with propensity-matched patients without a SW encounter. Of the 977 records, 300 were randomly selected for abstraction of needs addressed at the SW consultation using SDH categories established by Wilkinson and Marmot.

Results: Patient insurance status included 52\% Medicare and 32\% Medicaid. The SDHs most often addressed were social gradient (67\%; obtaining medications or health insurance) and social support (25\%). Among our total population, there were no significant improvements in glycosylated hemoglobin $\left(\mathrm{HbA}_{1 \mathrm{c}}\right)$, low-density lipoprotein (LDL) cholesterol, systolic blood pressure, or body mass index at least 3 months after the first SW consultation. For patients with uncontrolled diabetes $\left(\mathrm{HbA}_{1 \mathrm{c}}>9 \%\right.$ or $\mathrm{LDL}$ cholesterol $>130 \mathrm{mg} / \mathrm{dl}), \mathrm{HbA}_{1 \mathrm{c}}$ improved by 1.5 versus $1.1 \%$ for matched controls $(P=.03)$ and LDL improved by 37.7 versus $21.3 \mathrm{mg} / \mathrm{dl}$ for matched controls $(P=.002)$.

Conclusions: In this sample with a preponderance of Medicare and Medicaid patients, social workers most often assisted patients with diabetes in obtaining medications or health insurance. For patients with uncontrolled diabetes or cholesterol, a temporal association between SW consultation and improved disease control was noted. (J Am Board Fam Med 2017;30:35-43.)

Keywords: Ambulatory Care; Blood Pressure; Body Mass Index; Cholesterol, LDL; Diabetes Mellitus; Electronic Health Records; Hemoglobin A, Glycosylated; Health Insurance; Outpatients; Primary Health Care; Referral and Consultation; Retrospective Studies; Risk Factors; Social Determinants of Health; Social Support; Social Work; Social Workers

Health status is profoundly influenced by the social and economic conditions known as the social determinants of health. ${ }^{1}$ For patients with diabetes,

This article was externally peer reviewed.

Submitted 28 May 2016; revised 11 September 2016; accepted 13 September 2016.

From the Case Western Reserve University School of Medicine, Cleveland, OH (AJR); the Center for ValueBased Care Research, Medicine Institute, Cleveland Clinic, Cleveland (MBR, ADM-H); the Department of Bioethics, Cleveland Clinic, Cleveland (SLR); the Department of Internal Medicine, Cleveland Clinic, Cleveland $(\mathrm{AB})$; the Department of Quantitative Health Sciences, Cleveland Clinic, Cleveland (LK, ADM-H); and glycemic control is affected by lifestyle choices and medical treatment, ${ }^{2}$ but the underlying influences of social determinants of health are increasingly

the Cleveland Clinic Lerner College of Medicine of Case Western Reserve University, Cleveland (MBR, SLR, AB, ADM-H).

Funding: none.

Prior presentation: This was presented as an oral presentation at the Society of General Internal Medicine national meeting in Hollywood, Florida on May 13, 2016.

Conflict of interest: none declared.

Corresponding author: Anita D. Misra-Hebert, MD, MPH, Center for Value-Based Care Research, Medicine Institute, Cleveland Clinic, 9500 Euclid Ave, G10, Cleveland, OH 44195 (E-mail: misraa@ccf.org). 
being recognized. ${ }^{3,4}$ Some of these conditions may be amenable to intervention on the individual patient level and, if addressed, might help patients with diabetes attain better outcomes. ${ }^{5}$ However, addressing social determinants of health can be complex, and many physicians may feel unprepared to do so effectively. $6,7^{\circ}$

Within the patient-centered medical home, ${ }^{8,9}$ the clinical social worker is the team member best positioned to address social determinants of health. ${ }^{10-13}$ Previously, researchers in both the United States and Canada have attempted to elucidate the functions of health care social workers using surveys. ${ }^{14-16}$ However, the specific roles of social workers in routine primary care practice has not been systematically characterized. Interdisciplinary primary care teams consisting of a physician, nurse, and social worker can help decrease patient utilization of acute care services, ${ }^{17}$ but the individual effect of a consultation with a social worker for chronic disease control has not been well assessed. To better understand the role and impact of social workers in the primary care setting, we conducted a retrospective review of all patients with diabetes who had a social work consultation over a 1 -year period at 3 primary care sites. The purpose of our study was (1) to describe the specific patient needs addressed during social work consultations and (2) to assess the impact of social work consultation on diabetes and cardiovascular risk factor control.

\section{Methods}

In 2014, 3 primary care internal medicine sites in the Cleveland Clinic Health System each had 1 licensed social worker dedicated to providing services in the outpatient clinic. While all 3 sites are part of 1 health system, 1 of the sites serves a rural population while the other 2 are in urban settings. Through our electronic medical record, we identified all patients with diabetes who also had a social work consultation during 2014. A patient was identified as having diabetes if there were 2 encounters with an International Classification of Diseases, Ninth Revision code for diabetes, or 1 encounter with an International Classification of Diseases, Ninth Revision code for diabetes and at least 1 diabetes medication prescribed in the electronic medical record. For each of the 977 patients with a social work encounter, we identified patient age, sex, race, insurance status (Medicare, Medicaid, commercial, self-pay), estimated income by zip code, glycosylated hemoglobin $\left(\mathrm{HbA}_{1 \mathrm{c}}\right)$, low-density lipoprotein (LDL) cholesterol, systolic blood pressure (SBP), and body mass index (BMI). We then randomly selected a subset of 300 patients using the Excel (Microsoft Corp, Redmond, WA) random number function; this was applied to the unique patient identification numbers in the full data set of patients from each site to select 100 patients from each primary care site for abstraction of social work progress notes in their medical records. For each of these 300 patients we identified the patient needs addressed by the social worker using a standardized data abstraction sheet modeled after the social determinants of health classification established by Wilkinson and Marmot. ${ }^{1}$ We felt that reviewing this random subset of 300 records among those for the 977 patients with diabetes seen by a social worker in 2014 would appropriately allow us to describe the trends in specific needs addressed by the social workers for the total population. To the best of our knowledge, each of the licensed social workers at these 3 sites received no specific training from our health system in using the social determinants of health framework by Wilkinson and Marmot in their encounters. The protocol was approved by the institutional review board at the Cleveland Clinic.

The following social determinants of health classification established by Wilkinson and Marmot $^{1}$ was used during the medical record abstraction portion of our study to categorize the social workers' notes regarding the issues addressed during the encounter: (1) the social gradient, encompassing the impact that monetary assets, occupational level/security, and housing have on health; (2) stress, or the effects of continuous anxiety, insecurity, and low self-esteem; (3) early life, or the impact that previous emotional and developmental experiences of childhood and adolescence have on adult health; (4) social exclusion, which is the effects of being treated less than equal as a result of discrimination, debilitation, racism, or stigmatization (such as is experienced by ex-convicts, the homeless, and those who are mentally ill); (5) work, or the specific contribution of stress at work to overall health; (6) unemployment, or the increased risk of premature death experienced by the unemployed and their families; (7) social support, including the impact that both emotional and tangible 
support systems have on health; (8) addiction, which encompasses the effects of alcohol, nicotine, and drug dependence both as a result of social inequality as well as a means of increasing its impact; (9) food, or how access to healthy foods can influence chronic disease management and progression; and (10) transport, encompassing both the ability to arrive at appointments and walk/ exercise in safe environments. Psychiatric issues/ need for referral to a mental health provider was added as a separate category not specifically described by Wilkinson and Marmot. While psychiatric issues underlie several social determinants of health, such as social exclusion and addiction, we added this distinct category because of the frequency with which patients were referred to social workers to address this specific need. For each social work consultation designated for medical record abstraction, the patient needs addressed were categorized by 1 author (AJR). While formal reliability testing was not performed, all questions regarding specific categorization were discussed and agreed on by the senior author (ADM-H) through frequent communication. These categories were summarized as percentages and frequencies.

For all patients, standard outcome measures of diabetes and cardiovascular risk factor control $\left(\mathrm{HbA}_{1 \mathrm{c}}, \mathrm{LDL}\right.$ cholesterol, SBP, and $\left.\mathrm{BMI}\right)$ were abstracted at 2 time points. The baseline was the patient's last biometric value or test result before their first social work encounter in 2014, but after January 1, 2013. The follow-up time point was the first clinical or biometric value obtained at least 3 months after the first social work encounter. We chose at least 3 months after the first social work encounter as the follow-up time point because we believe this was the earliest time frame in which we might note a measurable change in clinical outcomes. For each outcome measure, we excluded any patient with clinical values missing at either baseline or follow-up. The Wilcoxon test was then used to compare baseline and follow-up measures of diabetes and cardiovascular risk factor control; this test is a commonly used statistical method to compare matched pairs and does not depend on the underlying distribution of the data.

In addition, we then examined 4 subsets of patients from the group of 977 patients who had either poorly controlled diabetes or an uncontrolled cardiovascular risk factor at baseline: those with $\mathrm{HbA}_{1 \mathrm{c}}>9 \%$, or LDL cholesterol $>130 \mathrm{mg} / \mathrm{dL}$, or
SBP $>160 \mathrm{mmHg}$, or BMI $>30 \mathrm{~kg} / \mathrm{m}^{2}$. Each subgroup was matched to a comparison group of diabetic patients from the same primary care sites without a social work encounter in 2014. In creating our comparison group, matching was based on propensity scores, which were generated using age, sex, race, insurance status (Medicare, Medicaid, commercial, self-pay), estimated income by zip code, and baseline measures of diabetes and cardiovascular risk factor control as covariates in a multivariable logistic model. Patients from the intervention and nonintervention groups were paired if their propensity scores were within a caliper distance of 0.2. After matching, comparison patients were assigned a dummy visit date to correspond with the first social work visit of the intervention patient in the matched pair, and baseline and follow-up values were extracted in the same manner as for the intervention patients. The Wilcoxon test was then used to compare baseline and follow-up measures of diabetes and cardiovascular risk factor control between the 2 groups. All analyses were performed using R Studio Version 3.0.2.

\section{Results}

We identified 977 patients with diabetes who had a social work consultation in 2014: 382 patients from clinic 1 (urban), 342 patients from clinic 2 (urban), and 253 patients from clinic 3 (rural). The mean age was 61 years; $64 \%$ were African American and $32 \%$ were white. Patient insurance status included $52 \%$ with Medicare and $32 \%$ with Medicaid. The subset of 300 patients chosen for medical record abstraction had demographic characteristics similar to those of the overall sample of 977 patients (Table 1). Most patients in both groups had either Medicare or Medicaid insurance.

The social determinants of health addressed during the social work consultation are summarized in Table 2. The most common social determinants addressed included issues related to the social gradient or to social support. Regarding the social gradient, the social worker assisted the patient in obtaining medications in $69 \%$ of these encounters, addressed insurance issues in $52 \%$, and addressed both in $28 \%$. Specifically, the social worker most often addressed the need for medications by assisting the patient in applying for diabetes medications at reduced or no cost through the drug manufacturer or from other drug assistance programs. Regarding social support, the social worker most often 
Table 1. Comparison of Baseline Characteristics of All Patients with Diabetes with a Social Work Consultation in 2014 at Three Primary Care Sites in One Health System vs. a Subgroup of Patients Randomly Selected for Medical Record Abstraction

\begin{tabular}{|c|c|c|c|}
\hline & $\begin{array}{c}\text { Patients with Diabetes with a } \\
\text { Social Work Consultation in } \\
2014(\mathrm{n}=977)^{*} \mathrm{n}(\%) \text { or } \\
\text { Mean (SD) }\end{array}$ & $\begin{array}{l}\text { Patients with Diabetes with a Social Work } \\
\text { Consultation in } 2014 \text { Randomly Selected } \\
\text { for Medical Record Abstraction }(\mathrm{n}=300)^{\dagger} \\
\mathrm{n}(\%) \text { or Mean (SD) }\end{array}$ & $P$ Value \\
\hline Female sex, n (\%) & $569(58)$ & $194(65)$ & .05 \\
\hline Race, n (\%) & & & .16 \\
\hline Black & $623(64)$ & $175(58)$ & \\
\hline White & $316(32)$ & $108(36)$ & \\
\hline Other & $38(4)$ & $17(6)$ & \\
\hline Insurance type, n (\%) & & & 1.00 \\
\hline Medicare & $510(52)$ & $154(51)$ & \\
\hline Medicaid & $311(32)$ & $88(29)$ & \\
\hline Commercial & $75(8)$ & $20(7)$ & \\
\hline Other & $89(9)$ & $38(13)$ & \\
\hline Age (years), Mean (SD) & $60.7(13.6)$ & $60.8(13.3)$ & .90 \\
\hline $\mathrm{HbA}_{1 \mathrm{c}}(\%)$, Mean (SD) & $7.8(2.2)$ & $7.9(2.1)$ & .37 \\
\hline LDL cholesterol (mg/dL), Mean (SD) & $97.2(38.9)$ & $96.3(39.4)$ & .76 \\
\hline SBP (mmHg), Mean (SD) & $132.9(20.9)$ & $131.5(18.8)$ & .31 \\
\hline BMI $\left(\mathrm{kg} / \mathrm{m}^{2}\right)$, Mean $(\mathrm{SD})$ & $33.7(9.3)$ & $34(9.7)$ & .30 \\
\hline
\end{tabular}

*Of the 977 patients, 382 were from clinic 1 (urban), 342 were from clinic 2 (urban), and 253 were from clinic 3 (rural). A total of 908 patients had data for glycosylated hemoglobin $\left(\mathrm{HbA}_{1 \mathrm{c}}\right), 884$ patients had data for low-density lipoprotein (LDL) cholesterol, 974 patients had data for systolic blood pressure (SBP), and 958 patients had data for body mass index (BMI).

${ }^{+}$Of the 300 patients, 100 were from clinic 1 (urban), 100 were from clinic 2 (urban), and 100 were from clinic 3 (rural).

BMI, body mass index; $\mathrm{HbA}_{1 \mathrm{c}}$, glycosylated hemoglobin; LDL, low-density lipoprotein; n, number; SBP, systolic blood pressure; SD, standard deviation.

assessed the patient's support with daily activities and assisted patients in acquiring different levels of home care assistance.

Table 3 shows diabetes and cardiovascular risk factor control for those patients from our study population with values recorded at both baseline and follow-up after the social work consultation. At baseline, patients had reasonable control of measures except for BMI, which was a mean of 33.7 $\mathrm{kg} / \mathrm{m}^{2}$. At least 3 months after the first social work consultation (median follow-up time, 163 days; range, 89-453 days), there were no statistically significant improvements in any of the measures.

Of all patients from our study population who saw a social worker and had data recorded at baseline and follow-up, 188 (32.6\%) had $\mathrm{HbA}_{1 \mathrm{c}}>9 \%$, 125 (36.2\%) had LDL cholesterol $>130 \mathrm{mg} / \mathrm{dL}, 89$ (10.2\%) had SBP >160 mmHg, and 523 (62.3\%) had a BMI $>30 \mathrm{~kg} / \mathrm{m}^{2}$ at baseline. The results of propensity matching for each of these groups are shown in Online Appendix Tables 1 to 4. Following the first social work consultation, improvements were observed in $\mathrm{HbA}_{1 \mathrm{c}}, \mathrm{SBP}$, and LDL cholesterol after at least 3 months (Table 4). Compared with similar propensity-matched patients with diabetes who did not have a social work consultation, those who saw a social worker had larger declines in $\mathrm{HbA}_{1 \mathrm{c}}$ and $\mathrm{LDL}$ cholesterol, but not SBP.

\section{Discussion}

In this retrospective review of social work consultations for primary care internal medicine patients with diabetes, we describe the role of a social worker in addressing the needs of patients with diabetes using an established framework of the social determinants of health. We found that social workers most commonly address the social gradient and social support categories. We also found that following a social work visit, subgroups of patients with poorly controlled diabetes or cardiovascular risk factors showed improvements in control of diabetes, blood pressure, and LDL cholesterol, and that improvements in glycemic control and LDL cholesterol were significantly larger than those seen among propensity-matched patients who did not see a social worker. 
Table 2. Social Determinants of Health Addressed for 300 Patients Seen by a Social Worker at Three Primary Care Sites in 2014

\begin{tabular}{|c|c|c|}
\hline $\begin{array}{l}\text { SDH Classification Established by Wilkinson } \\
\text { and } \text { Marmot }^{1}\end{array}$ & $\begin{array}{l}\text { Patients for Whom the SDH } \\
\text { Was Addressed }(\mathrm{N}=300)^{*}\end{array}$ & Examples from Social Work Note \\
\hline $\begin{array}{l}\text { Social Gradient: impact of monetary assets, } \\
\text { occupational security/level, and housing } \\
\text { circumstances }\end{array}$ & $200(67)$ & $\begin{array}{l}\text { - Assisted patient in applying for medication } \\
\text { assistance program } \\
\text { - Assisted patient in completing Medicaid } \\
\text { application } \\
\text { - Provided patient information regarding } \\
\text { subsidized housing } \\
\text { - Directed patient to financial assistance } \\
\text { program for aid in affording home utilities }\end{array}$ \\
\hline $\begin{array}{l}\text { Social Support: impact of reliable emotional } \\
\text { and tangible support systems }\end{array}$ & $75(25)$ & $\begin{array}{l}\text { - Assessed patient's support system for daily } \\
\text { activities } \\
\text { - Connected patient to home care nursing } \\
\text { assistance } \\
\text { - Discussed with patient their sources of } \\
\text { emotional support }\end{array}$ \\
\hline $\begin{array}{l}\text { Transport: the means to access the health } \\
\text { system and exercise in safe environments }\end{array}$ & $43(14)$ & $\begin{array}{l}\text { - Arranged patient's transportation to and } \\
\text { from physician appointments via hospital } \\
\text { van } \\
\text { - Assisted patient in completing application } \\
\text { for cost-subsidized public transportation }\end{array}$ \\
\hline $\begin{array}{l}\text { Psychiatric Issues: need for referral to mental } \\
\text { health } \text { provider }^{\dagger}\end{array}$ & $37(12)$ & $\begin{array}{l}\text { - Referred patient to on-site psychiatrist } \\
\text { - Referred patient to off-site counselor }\end{array}$ \\
\hline $\begin{array}{l}\text { Unemployment: increased risk of premature } \\
\text { death }\end{array}$ & $14(5)$ & $\begin{array}{l}\text { - Discussed patient's recent unemployment } \\
\text { and future employment goals } \\
\text { - Provided patient information in renewing } \\
\text { occupational license } \\
\text { - Assisted patient in obtaining proof of } \\
\text { disability }\end{array}$ \\
\hline Food: access to affordable healthy options & $12(4)$ & $\begin{array}{l}\text { - Encouraged patient to apply for food } \\
\text { stamps } \\
\text { - Educated patient regarding different home } \\
\text { meal services }\end{array}$ \\
\hline $\begin{array}{l}\text { Stress: effects of anxiety, insecurity, low self- } \\
\text { esteem }\end{array}$ & $11(4)$ & $\begin{array}{l}\text { - Briefly discussed patient's stress coping } \\
\text { mechanisms } \\
\text { - Listened to patient describe stress of } \\
\text { difficult marriage }\end{array}$ \\
\hline $\begin{array}{l}\text { Social Exclusion: effects of discrimination, } \\
\text { debilitation, racism, stigmatization }\end{array}$ & $8(3)$ & $\begin{array}{l}\text { - Discussed patient's difficulties upon recent } \\
\text { release from prison } \\
\text { - Referred patient struggling with blindness } \\
\text { to support center to help increase quality } \\
\text { of life }\end{array}$ \\
\hline $\begin{array}{l}\text { Addiction: impact of alcohol, nicotine, and } \\
\text { drug dependence }\end{array}$ & $6(2)$ & $\begin{array}{l}\text { - Discussed different smoking cessation } \\
\text { resource options } \\
\text { - Referred patient to on-site alcohol } \\
\text { specialist }\end{array}$ \\
\hline Work: impact of stress at work & $3(1)$ & $\begin{array}{l}\text { - Provided patient information regarding } \\
\text { job retraining opportunities following } \\
\text { patient's recent injury }\end{array}$ \\
\hline $\begin{array}{l}\text { Early Life: impact of emotional and } \\
\text { developmental experiences of childhood } \\
\text { and adolescence }\end{array}$ & $2(1)$ & $\begin{array}{l}\text { - Discussed how patient was affected by } \\
\text { early relationships with family members } \\
\text { - Discussed patient's journey as an } \\
\text { immigrant to this country }\end{array}$ \\
\hline
\end{tabular}

Data are $\mathrm{n}(\%)$.

*The total of 300 includes 100 patients from each of 3 clinic sites.

${ }^{\dagger}$ Category added to the classification by Wilkinson and Marmot. ${ }^{1}$

$\mathrm{SDH}$, social determinant of health. 
Table 3. Measures of Diabetes and Cardiovascular Risk Factor Control for Patients with a Social Work Consultation in 2014 and with Values at Both Baseline and at Least 3-Month Follow-up

\begin{tabular}{lcrrr}
\hline $\begin{array}{l}\text { Measures of Diabetes and } \\
\text { Cardiovascular Risk Factor Control }\end{array}$ & $\begin{array}{c}\text { Patients with Clinical Values } \\
\text { at Baseline and Follow-up }\end{array}$ & Baseline* $^{*}$ & Follow-up $^{\dagger}$ & $P$ Value $^{+}$ \\
\hline Mean HbA & & & 7.9 & .97 \\
Mean LDL cholesterol $(\mathrm{mg} / \mathrm{dL})$ & 576 & 97.2 & 94.3 & .48 \\
Mean SBP $(\mathrm{mmHg})$ & 345 & 132.9 & 133.5 & .72 \\
Mean BMI $\left(\mathrm{kg} / \mathrm{m}^{2}\right)$ & 866 & 33.7 & 33.8 \\
\hline
\end{tabular}

*The last biometric value or test result recorded before the first SW encounter in 2014.

${ }^{+}$The first biometric value or test result recorded at least 3 months after the first SW encounter in 2014.

BMI, body mass index; $\mathrm{HbA}_{1 \mathrm{c}}$, glycosylated hemoglobin; LDL, low-density lipoprotein; SBP, systolic blood pressure; SW, social work.

While it has been suggested that social workers have the potential to function in diverse roles such as educators, counselors, and resource brokers to specifically address underlying influences of diabetes control, ${ }^{18}$ the nature of this involvement has not been systematically investigated in an outpatient primary care setting. In our study, the social worker's role as a resource broker was evident. The most common categories of patient needs addressed in these consultations were helping patients obtain medications or insurance (social gradient) and assessing the need for and connecting patients to home health care services (social support). Of note, in Wilkinson and Marmot's ${ }^{1}$ conception of the social determinants of health, the social gradient encompasses the impact of occupational class, monetary assets, housing, and education level on the health and life expectancy of patients. In our study of patients seen by social workers in the United States, the social factors defining the social gradient predominately manifested as barriers to accessing health care and different levels of health care services, highlighting health care access as a significant social determinant of health. Rather than directly addressing patients' occupational level or finances, social workers most often addressed the impact of the these factors on the ability of patients to obtain medications or adequate health care insurance. This is consistent with a survey of health care social workers in Canada, including but not limited to those in primary care clinics, in which social workers reported that they most commonly addressed access to health care services and resources. ${ }^{15}$

In our study, social workers rarely addressed or counseled patients regarding daily stress, work-related stressors, or addiction. It has been suggested that social workers can have a larger impact in addressing issues of mental health in the broader primary care setting. ${ }^{19-21}$ In fact, existing evidence links stress and addiction to poor diabetes control, ${ }^{5,22,23}$ and the link between depression and diabetes has been an interest of study for some time, albeit with varying results. ${ }^{24-26}$ In our study, social workers addressed psychiatric issues in $12 \%$ of all encounters. In all these cases the social workers referred patients to specific mental health providers. While this finding may represent practice patterns of social workers in our health system, or the comfort level of an individual social worker in providing counseling, it is possible that time spent in direct counseling may not consistently be documented as such. Our results may also offer some credence to the opinion that the role of providing tangible resources for patients can be so time-consuming that it detracts from the social worker's role as a counselor. ${ }^{13} \mathrm{We}$ hope to investigate this question further in future studies.

Overall, for the patients with diabetes included in our study, we found no significant improvement in clinical markers of diabetes and cardiovascular risk factor control associated with social work consultation. These findings were not surprising because the study population had relatively well-controlled $\mathrm{HbA}_{1 \mathrm{c}}$, LDL cholesterol, and SBP before the social work consultation. In terms of BMI, we also did not expect a significant change to occur because of the relatively difficult nature of weight loss, for which medications are not regularly prescribed.

However, for the subset of patients with poorly controlled diabetes and cardiovascular risk factors before the social work consultation, we observed improved control of diabetes, blood pressure, and 
LDL cholesterol following the social work consultation, and improvements in glycemic control and LDL cholesterol were significantly larger than those seen among patients who did not see a social worker. In previous studies, material insecuritiesincluding cost-related medication underuse-were associated with poor diabetes control. ${ }^{27,28}$ Our results may also be consistent with a study of patients with uncontrolled diabetes in which enrollment in a medication assistance program led to improved disease control. ${ }^{29}$ In terms of diabetes and cardiovascular risk factors, social work consultations seem most beneficial for patients with poorly controlled diabetes who need assistance obtaining medications and/or health insurance. However, other benefits of the social work consultation, such as counseling or support and improved access to community resources, may have also contributed to these improvements; these factors were not specifically measured in our analysis of these subgroups.

Research suggests that physicians are not prepared to adequately address cost-related medication underuse. Consequently, patients may not learn of or benefit from helpful resources such as drug assistance programs. ${ }^{30,31}$ Among physicians, the most common self- reported barriers to addressing this need were insufficient time and their belief that they did not have a solution, emphasizing the importance of nonphysician members of the medical team. ${ }^{32}$ Our study suggests that social workers can play a key role in addressing costrelated medication underuse. As primary care delivery models evolve, however, other members of the clinical care team, such as pharmacists or navigators embedded in a patient-centered medical home, may also fulfill this role.

Our results also may support the literature regarding the impact of low social support on poor glycemic control. ${ }^{5,33}$ In our study, the social worker often addressed social support in the area of tangible support by assessing and addressing patients' need for additional assistance with daily activities. Addressing social support in social work encounters may have been a factor contributing to the improvement in $\mathrm{HbA}_{1 \mathrm{c}}$ we observed for our subset of patients with poor diabetes control at baseline.

\section{Limitations}

While our work contributes to the understanding of the potential role of social workers for patients with diabetes, our study has several limitations. Our 
findings are limited to primary care internal medicine sites that largely serve Medicare and Medicaid patients within a single health system, and the generalizability to family medicine practices is unknown. In addition, our results could have been affected by the documentation practices of each individual social worker. Although the notes from social workers at all 3 primary care sites appeared to be complete, some notes included more detailed descriptions of encounters, creating the possibility that we missed needs that were addressed but not documented. Regarding assessment of the clinical impact of the encounters, our study was also limited by its retrospective nature and the potential for confounding. For example, we know that for many of the 300 patients whose charts were included in the medical record abstraction, the social worker assisted them in applying for medication assistance and/or health insurance. While we believe that these measures helped many of these patients obtain medications that they previously could not, we could not directly study whether this occurred. Future prospective studies that would also control for other interval events between the social work consultation and follow-up time period should be aimed at investigating exactly how social work encounters may help patients to resolve individual social determinants of health issues. Further understanding of these processes would help to establish both best practices for social work consultation-including the optimal number of social work consultations needed-and to support specific relationships of social work consultation to the types of clinical improvements that we observed. In addition, it is also possible that physicians may have referred only those patients whom they thought most likely to benefit from a social work consultation, and these patients may have differed from those not referred, possibly with regard to their motivation to improve health. Our findings were also limited to patients with both baseline and follow-up values. Those excluded because of missing values may have differed in their response to the social work consultation.

\section{Conclusions}

Social determinants of health may affect diabetes and cardiovascular risk factor control and serve as important targets for intervention for patients with diabetes. A social worker, as part of a primary care team, may be best suited to address the social determinants of health. In our study, social workers most often addressed social determinants in the role of resource broker, by assisting patients in applying for medication assistance or health insurance. For patients with uncontrolled diabetes or cholesterol, a temporal association between social work consultation and improved disease control was noted. Future studies should aim to examine further how and which aspects of social work consultation may specifically affect the level of chronic disease control.

The authors sincerely thank Nancy Fenner, LISW, for providing valuable insight into her role as a social worker during the planning of this project.

To see this article online, please go to: http://jabfm.org/content/ 30/1/35.full.

\section{References}

1. Wilkinson RG, Marmot MG. Social determinants of health: the solid facts. Geneva, Switzerland: World Health Organization; 2003.

2. Knowler WC, Barrett-Connor E, Fowler SE, et al. Reduction in the incidence of type 2 diabetes with lifestyle intervention or metformin. N Engl J Med 2002;346:393-403.

3. Walker RJ, Smalls BL, Campbell JA, Strom Williams JL, Egede LE. Impact of social determinants of health on outcomes for type 2 diabetes: a systematic review. Endocrine 2014;47:29-48.

4. Clark ML, Utz S. Social determinants of type 2 diabetes and health in the United States. World J Diabetes 2014;5:296.

5. Walker RJ, Smalls BL, Egede LE. Social determinants of health in adults with type 2 diabetes-contribution of mutable and immutable factors. Diabetes Res Clin Pract 2015;110:193-201.

6. Behforouz HL, Drain PK, Rhatigan JJ. Rethinking the social history. N Engl J Med 2014;371:1277-9.

7. Sharfstein JM. JAMA forum: health care and poverty. news@JAMA. September 24, 2014. Available from: http://newsatjama.jama.com/2014/09/24/jamaforum-health-care-and-poverty/. Accessed February 3, 2016.

8. Coordinating care for adults with complex care needs in the patient-centered medical home: challenges and solutions. White paper. AHRQ publication no. 12-0010-EF. Rockville, MD: Agency for Healthcare Research and Quality; 2012. Available from: http://pcmh.ahrq.gov/sites/default/files/ attachments/Coordinating\% 20Care \% 20 for $\% 20$ Adults\%20with \%20Complex\%20Care\%20Needs. pdf. Accessed November 9, 2016. 
9. Andrews CM, Darnell JS, McBride TD, Gehlert S. Social work and implementation of the Affordable Care Act. Health Soc Work. 2013;38:67-71.

10. Keefe B, Geron SM, Enguidanos S. Integrating social workers into primary care: physician and nurse perceptions of roles, benefits, and challenges. Soc Work Health Care 2009;48:579-96.

11. Reckrey JM, Gettenberg G, Ross H, Kopke V, Soriano $\mathrm{T}$, Ornstein $\mathrm{K}$. The critical role of social workers in home-based primary care. Soc Work Health Care 2014;53:330-43.

12. Jani JS, Tice C, Wiseman R. Assessing an interdisciplinary health care model: the governor's Wellmobile program. Soc Work Health Care 2012;51:441-56.

13. Craig SL, Betancourt I, Muskat B. Thinking big, supporting families and enabling coping: the value of social work in patient and family centered health care. Soc Work Health Care 2015;54:422-43.

14. Whitaker T, Weismiller T, Clark E. Assuring the sufficiency of a frontline workforce: a national study of licensed social workers. Special report: social work services for children and families. Washington, DC: National Association of Social Workers; 2006.

15. Craig SL, Bejan R, Muskat B. Making the invisible visible: are health social workers addressing the social determinants of health? Soc Work Health Care 2013;52:311-31.

16. Horevitz E, Manoleas P. Professional competencies and training needs of professional social workers in integrated behavioral health in primary care. Soc Work Health Care 2013;52:752-87.

17. Sommers LS, Marton KI, Barbaccia JC, Randolph J. Physician, nurse, and social worker collaboration in primary care for chronically ill seniors. Arch Intern Med. 2000;160:1825-33.

18. DeCoster VA. Challenges of type 2 diabetes and role of health care social work: a neglected area of practice. Health Soc Work 2001;26:26-37.

19. Badger LW, Ackerson B, Buttell F, Rand EH. The case for integration of social work psychosocial services into rural primary care practice. Health Soc Work 1997;22:20-9.

20. Davis TS, Guada J, Reno R, et al. Integrated and culturally relevant care: a model to prepare social workers for primary care behavioral health practice. Soc Work Health Care 2015;54:909-38.

21. Craig S, Frankford R, Allan K, et al. Self-reported patient psychosocial needs in integrated primary health care: a role for social work in interdisciplinary teams. Soc Work Health Care 2016;55:41-60.
22. Rubin RR, Peyrot M. Psychosocial problems and interventions in diabetes. A review of the literature. Diabetes Care 1992;15:1640-57.

23. Moayad N, Balcázar H, Pedregón V, Velasco L, Bayona M. Do acculturation and family cohesiveness influence severity of diabetes among Mexican Americans? Ethn Dis 2006;16:452-9.

24. Gary TL, Crum RM, Cooper-Patrick L, Ford D, Brancati FL. Depressive symptoms and metabolic control in African-Americans with type 2 diabetes. Diabetes Care 2000;23:23-9.

25. Kumari M, Head J, Marmot M. Prospective study of social and other risk factors for incidence of type 2 diabetes in the Whitehall II study. Arch Intern Med 2004;164:1873-80.

26. Chiu C-J, Wray LA, Beverly EA, Dominic OG. The role of health behaviors in mediating the relationship between depressive symptoms and glycemic control in type 2 diabetes: a structural equation modeling approach. Soc Psychiatry Psychiatr Epidemiol 2009; 45:67-76.

27. Berkowitz SA, Meigs JB, DeWalt D, et al. Material need insecurities, control of diabetes mellitus, and use of health care resources: results of the Measuring Economic Insecurity in Diabetes Study. JAMA Intern Med 2015;175:257-65.

28. Piette JD, Wagner TH, Potter MB, Schillinger D. Health insurance status, cost-related medication underuse, and outcomes among diabetes patients in three systems of care. Med Care 2004;42:102-9.

29. Horswell R, Wascom C, Cerise F, Besse J, Johnson J. Diabetes Mellitus Medication Assistance Program: relationship of effectiveness to adherence. J Health Care Poor Underserved 2008;19:677-86.

30. Piette JD, Heisler M, Wagner TH. Cost-related medication underuse: do patients with chronic illnesses tell their doctors? Arch Intern Med 2004;164: $1749-55$.

31. Piette JD, Heisler M, Horne R, Caleb Alexander G. A conceptually based approach to understanding chronically ill patients' responses to medication cost pressures. Soc Sci Med 2006;62:846-57.

32. Alexander GC, Casalino LP, Tseng C-W, McFadden D, Meltzer DO. Barriers to patient-physician communication about out-of-pocket costs. J Gen Intern Med 2004;19:856-60.

33. Walker RJ, Gebregziabher M, Martin-Harris B, Egede LE. Quantifying direct effects of social determinants of health on glycemic control in adults with type 2 diabetes. Diabetes Technol Ther 2015;17: $80-7$. 
Appendix Table 1: Propensity-Matched Groups for Glycosylated Hemoglobin

\begin{tabular}{|c|c|c|c|}
\hline Variables & $\begin{array}{c}\text { Comparison } \\
\text { Group } \\
(\mathrm{n}=188)\end{array}$ & $\begin{array}{c}\text { Intrevention } \\
\text { Group } \\
(\mathrm{n}=188)\end{array}$ & $P$ Value \\
\hline Sex, n (\%) & & & .84 \\
\hline Female & $88(46.8)$ & $90(47.9)$ & \\
\hline Male & $100(53.2)$ & $98(52.1)$ & \\
\hline Race & & & .81 \\
\hline Black & $119(63.3)$ & $125(66.5)$ & \\
\hline Other & $8(4.3)$ & $7(3.7)$ & \\
\hline White & $61(32.4)$ & $56(29.8)$ & \\
\hline Insurance type, n (\%) & & & .94 \\
\hline Private & $24(12.8)$ & $20(10.6)$ & \\
\hline Medicare & $82(43.6)$ & $84(44.7)$ & \\
\hline Medicaid & $74(39.4)$ & $76(40.4)$ & \\
\hline Self-pay & $8(4.3)$ & $8(4.3)$ & \\
\hline Age (years) & & & .89 \\
\hline Minimum & 20.6 & 23.8 & \\
\hline Q1 & 48.1 & 48.7 & \\
\hline Median & 56.4 & 56.5 & \\
\hline Q3 & 64.1 & 64.7 & \\
\hline Maximum & 87.2 & 87.3 & \\
\hline Mean & 56.1 & 56.4 & \\
\hline SD & 13.9 & 12.9 & \\
\hline $\mathrm{HbA}_{1 \mathrm{c}}(\%)$ & & & .48 \\
\hline Minimum & 9 & 9 & \\
\hline Q1 & 9.7 & 9.9 & \\
\hline Median & 10.7 & 10.8 & \\
\hline Q3 & 12.1 & 12 & \\
\hline Maximum & 17.2 & 17.3 & \\
\hline Mean & 11.1 & 11.2 & \\
\hline SD & 1.7 & 1.7 & \\
\hline Income $(\$)$ & & & .23 \\
\hline Minimum & 11,792 & 11,792 & \\
\hline Q1 & 23,161 & 24,312 & \\
\hline Median & $31,918.5$ & 35,110 & \\
\hline Q3 & 46,475 & 46,475 & \\
\hline Maximum & 72,010 & 72,010 & \\
\hline Mean & $34,719.1$ & $35,877.1$ & \\
\hline SD & $13,734.2$ & $12,337.8$ & \\
\hline
\end{tabular}

HbA1c, glycosylated hemoglobin; SD, standard deviation.
Appendix Table 2: Propensity-Matched Groups for Body Mass Index

\begin{tabular}{|c|c|c|c|}
\hline Variables & $\begin{array}{c}\text { Comparison } \\
\text { Group } \\
(\mathrm{n}=523)\end{array}$ & $\begin{array}{c}\text { Intrevention } \\
\text { Group } \\
(\mathrm{n}=523)\end{array}$ & $P$ Value \\
\hline Sex, n (\%) & & & .70 \\
\hline Female & $321(61.4)$ & $327(62.5)$ & \\
\hline Male & $202(38.6)$ & $196(37.5)$ & \\
\hline Race, n (\%) & & & .25 \\
\hline Black & $325(62.1)$ & $326(62.3)$ & \\
\hline Other & $6(1.1)$ & $13(2.5)$ & \\
\hline White & $192(36.7)$ & $184(35.2)$ & \\
\hline Insurance type, n (\%) & & & .23 \\
\hline Private & $61(11.7)$ & $42(8)$ & \\
\hline Medicare & $273(52.2)$ & $274(52.4)$ & \\
\hline Medicaid & $182(34.8)$ & $200(38.2)$ & \\
\hline Self-pay & $7(1.3)$ & $7(1.3)$ & \\
\hline Age (years) & & & .78 \\
\hline Minimum & 21.8 & 21.8 & \\
\hline Q1 & 49.5 & 49.5 & \\
\hline Median & 58.6 & 57.1 & \\
\hline Q3 & 68.4 & 67.7 & \\
\hline Maximum & 89.7 & 92 & \\
\hline Mean & 58.4 & 58.4 & \\
\hline SD & 13.3 & 13.2 & \\
\hline BMI $\left(\mathrm{kg} / \mathrm{m}^{2}\right)$ & & & .14 \\
\hline Minimum & 30 & 30 & \\
\hline Q1 & 32.6 & 33 & \\
\hline Median & 36.7 & 37.4 & \\
\hline Q3 & 41.6 & 43 & \\
\hline Maximum & 61.7 & 78 & \\
\hline Mean & 38.2 & 39.2 & \\
\hline SD & 6.7 & 8 & \\
\hline Income (\$) & & & .44 \\
\hline Minimum & 14,227 & 11,792 & \\
\hline Q1 & 23,205 & 23,205 & \\
\hline Median & 36,356 & 35,833 & \\
\hline Q3 & 46,475 & 46,475 & \\
\hline Maximum & 98,260 & 90,599 & \\
\hline Mean & 36,927 & $36,017.7$ & \\
\hline SD & 14,314 & 13,487 & \\
\hline
\end{tabular}

BMI, body mass index; SD, standard deviation. 
Appendix Table 3: Propensity-Matched Groups for Systolic Blood Pressure

\begin{tabular}{|c|c|c|c|}
\hline Variables & $\begin{array}{c}\text { Comparison } \\
\text { Group } \\
(\mathrm{n}=89)\end{array}$ & $\begin{array}{c}\text { Intrevention } \\
\text { Group } \\
(\mathrm{n}=89)\end{array}$ & $P$ Value \\
\hline Sex, n (\%) & & & .54 \\
\hline Female & $55(61.8)$ & $51(57.3)$ & \\
\hline Male & $34(38.2)$ & $38(42.7)$ & \\
\hline Race, n (\%) & & & .57 \\
\hline Black & $69(77.5)$ & $72(80.9)$ & \\
\hline Other & $0(0)$ & $1(1.1)$ & \\
\hline White & $20(22.5)$ & $16(18)$ & \\
\hline Insurance type, n (\%) & & & .96 \\
\hline Private & $8(9)$ & $8(9)$ & \\
\hline Medicare & $63(70.8)$ & $60(67.4)$ & \\
\hline Medicaid & $16(16)$ & $19(21.3)$ & \\
\hline Self-pay & $2(2.2)$ & $2(2.2)$ & \\
\hline Age (years) & & & .37 \\
\hline Minimum & 23.8 & 29.1 & \\
\hline Q1 & 56.9 & 54.9 & \\
\hline Median & 66.4 & 63 & \\
\hline Q3 & 75 & 74.7 & \\
\hline Maximum & 89.7 & 91.4 & \\
\hline Mean & 65.1 & 63.8 & \\
\hline SD & 13.7 & 14 & \\
\hline SBP (mmHg) & & & .28 \\
\hline Minimum & 160 & 160 & \\
\hline Q1 & 164 & 166 & \\
\hline Median & 168 & 170 & \\
\hline Q3 & 180 & 182 & \\
\hline Maximum & 215 & 230 & \\
\hline Mean & 173.5 & 175.1 & \\
\hline SD & 13 & 13.7 & \\
\hline Income (\$) & & & .43 \\
\hline Minimum & 19,371 & 11,792 & \\
\hline Q1 & 24,312 & 23,205 & \\
\hline Median & 31,481 & 31,120 & \\
\hline Q3 & 46,475 & 46,241 & \\
\hline Maximum & 98,260 & 72,010 & \\
\hline Mean & $35,511.6$ & 33,427 & \\
\hline SD & $13,615.4$ & $12,801.5$ & \\
\hline
\end{tabular}

SBP, systolic blood pressure; SD, standard deviation.
Appendix Table 4: Propensity-Matched Groups for Low-Density Lipoprotein Cholesterol

\begin{tabular}{|c|c|c|c|}
\hline Variables & $\begin{array}{c}\text { Comparison } \\
\text { Group } \\
(\mathrm{n}=125)\end{array}$ & $\begin{array}{c}\text { Intrevention } \\
\text { Group } \\
(\mathrm{n}=125)\end{array}$ & $P$ Value \\
\hline Sex, n (\%) & & & .52 \\
\hline Female & $72(57.6)$ & $77(61.6)$ & \\
\hline Male & $53(42.4)$ & $48(38.4)$ & \\
\hline Race, n (\%) & & & .95 \\
\hline Black & $80(64)$ & $82(65.6)$ & \\
\hline Other & $5(4)$ & $4(3.2)$ & \\
\hline White & $40(32)$ & $39(31.2)$ & \\
\hline Insurance type, n (\%) & & & .91 \\
\hline Private & $7(5.6)$ & $6(4.8)$ & \\
\hline Medicare & $76(60.8)$ & $74(59.2)$ & \\
\hline Medicaid & $42(33.6)$ & $45(36)$ & \\
\hline Self-pay & $0(0)$ & $0(0)$ & \\
\hline Age (years) & & & .18 \\
\hline Minimum & 29.9 & 30.4 & \\
\hline Q1 & 53.7 & 51.3 & \\
\hline Median & 62.4 & 57.9 & \\
\hline Q3 & 69.3 & 68.2 & \\
\hline Maximum & 89.9 & 85.5 & \\
\hline Mean & 61.8 & 59.8 & \\
\hline SD & 12.6 & 11.8 & \\
\hline LDL cholesterol (mg/dL) & & & .71 \\
\hline Minimum & 130 & 130 & \\
\hline Q1 & 136 & 136 & \\
\hline Median & 145 & 148 & \\
\hline Q3 & 166 & 165 & \\
\hline Maximum & 273 & 301 & \\
\hline Mean & 155.5 & 155.9 & \\
\hline SD & 28.4 & 28.9 & \\
\hline Income (\$) & & & .63 \\
\hline Minimum & 14,227 & 11,792 & \\
\hline Q1 & 23,205 & 24,312 & \\
\hline Median & 31,481 & 37,594 & \\
\hline Q3 & 46,475 & 46,475 & \\
\hline Maximum & 64,200 & 72,010 & \\
\hline Mean & $35,252.9$ & $35,826.9$ & \\
\hline SD & $13,015.4$ & $12,902.5$ & \\
\hline
\end{tabular}

LDL, low-density lipoprotein; SD, standard deviation. 